\title{
Comparation of the Montreal Cognitive Assessment Score Indonesian Version (MoCA-INA) and the Personal And Social Performance Scale (PSP) Score in Schizophrenic male with Dominant Negative Symptoms and Non-Dominant Negative Symptoms at Mental Hospital Prof. DR. M. Ildrem Medan
}

\author{
Huzaipah $^{1}$, Bahagia Loebis ${ }^{2}$, Vita Camellia ${ }^{3}$ \\ DOI: 10.29322/IJSRP.11.02.2021.p11045 \\ http://dx.doi.org/10.29322/IJSRP.11.02.2021.p11045
}

Department of Psychiatry, Faculty of Medicine, Universitas Sumatera Utara, Medan, Indonesia

\begin{abstract}
Objective: Schizophrenia is a serious neuropsychiatric disorder involving major disturbances in the patient's thinking, perception, emotions and behavior, associated with morbidity, disability, and a large potential for death, thus carrying a large socioeconomic burden on patients, caregivers and health care providers . Predictors of disability include cognitive deficits and negative symptoms, both of which account for the disability in schizophrenia that is difficult to treat.
\end{abstract}

Aims: To determine the comparison of the Montreal Cognitive Assessment Score Indonesian Version (MOCA-INA) and Personal and Social Performance Scale (PSP) scores in Schizophrenic male with Dominant Negative Symptoms and NonDominant Negative Symptoms at Mental Hospital Prof. DR. M. Ildrem Medan.

Methods: This is an analytical study with a cross-sectional study approach, conducted at the Mental Hospital Prof. DR. M. Ildrem Medan, from January to June 2019 with 80 subjects include (40 subjects with dominant negative symptoms and 40 subjects with non-dominant negative symptoms) who met the inclusion and exclusion criteria. Statistical test analysis used the Mann-Whitney $\mathrm{U}$ test.

Results: The results showed that the median MoCA-INA score for schizophrenic male with dominant negative symptoms was 20.00 with a minimum score of 16.00 , the maximum score was 24.00 and the median MoCA-INA score for schizophrenic male with non-dominant negative symptoms was 21.50 with a minimum score of 16.00 and a maximum score of 26.00. The median PSP score of schizophrenic male with dominant negative symptoms was 55.00 with a minimum score of 45.00 , the maximum score was 70.00 and the median PSP score for schizophrenic male with non-dominant negative symptoms was 56.50 with the minimum score is 45.00 and the maximum score is 71.00 .

Conclusion: There was no difference in the MoCA-INA score between Schizophrenic male with Dominant Negative Symptoms and non-Dominant Negative Symptoms with $\mathrm{p}$ value $=$ 0.114. There was no difference in the PSP score between
Schizophrenic male with Dominant Negative Symptoms and nonDominant Negative Symptoms with with p value $=0.174$.

Index Terms- Schizophrenia, negative symptoms, MoCA-INA score, PSP score

\section{INTRODUCTION}

Vegative symptoms in schizophrenia contribute more to 1 impaired quality of life and poor function than positive symptoms. Primary negative symptoms, including flat affect, allogia and avolition have a prevalence rate of about $20 \%$ in patients diagnosed with schizophrenia. The prevalence of negative symptoms in schizophrenia is very high and the most frequent negative symptoms are social withdrawal $(45.8 \%)$, emotional withdrawal (39.1\%), bad rapport (35.8\%) and blunt affect (33.1\%). In addition, patients who had higher negative symptom scores in schizophrenia were associated with poorer functioning, those who showed higher social withdrawal and worse relationships were more likely to be unemployed, patients with higher emotional and social withdrawal were more likely to be unemployed. less likely to be married / single and finally, individuals with higher emotional withdrawal are more likely to receive higher doses of antipsychotics [1].

Schizophrenia is a chronic and debilitating neuropsychiatric disorder, characterized by heterogeneous symptoms, including positive, negative symptoms first described in the 1920s and later redefined. Schizophrenia is also associated with multifaceted cognitive deficits, most prominently in the areas of attention, memory and executive function and social cognition. Schizophrenia has a devastating impact on nearly every aspect of a person's life and is associated with significant social, psychological and occupational dysfunction, even when psychotic symptoms have been controlled with antipsychotics [2].

Negative symptoms are a cause of long-term morbidity, poor functional outcome, and high rates of disability in patients with schizophrenia. They have a profound impact on the daily 
functioning of the patient affecting the ability to live independently, to carry out activities of daily life, to be socially active, to maintain personal relationships, and to work and study. Research evidence suggests that negative symptoms of schizophrenia contribute more to impaired quality of life and poor function than positive symptoms and that their severity is associated with a lower quality of life [3],[4].

Negative symptoms are a major contributor to low levels of functioning and decline in most patients with schizophrenia, because patients with poor motivation are unable to function at school or at work, are unable to maintain relationships with family and friends in the face of unresponsive influences, and do not develop personal interest when experiencing anhedonia, apathy, and inattentive. Negative symptoms affect the patient's ability to cope with daily activities and negatively impact their quality of life. Negative symptoms are relatively common and cause many long-term morbidity and poor functional outcomes in patients with schizophrenia [3], [4]. Diagnostic and statistical manual of mental disorder -Text Revision 4th edition (DSM-IV TR) lists social / occupational dysfunction as secondary of the six diagnostic criteria for schizophrenia. The description of social function covers three broad domains: work / academic, interpersonal relationships, and self-care [2].

Aims of this studi is determine the comparison of the Montreal Cognitive Assessment Score Indonesian Version (MOCA-INA) and Personal and Social Performance Scale (PSP) scores in Schizophrenic male with Dominant Negative Symptoms and Non-Dominant Negative Symptoms at Mental Hospital Prof. DR. M. Ildrem Medan.

\section{METHODS}

This study is a two-group, non-independent numerical comparative analytic study using the Cross-Sectional Study approach, which assesses the comparison of the Montreal Cognitive Assessment Score Indonesian Version (MOCA-INA) and Personal and Social Performance Scale (PSP) scores in Schizophrenic male with Dominant Negative Symptoms and NonDominant Negative Symptoms, were sample divided into two sample groups, namely first group is schizophrenic male with dominant negative symptoms and second group is a group is schizophrenic male with Non-dominant negative symptoms. The total number of subjects for the two groups was 80 subjects, where each group consisted of 40 subjects who had met the inclusion criteria. Before filling out the questionnaire, the researcher also obtained the consent of the research subjects through filling out the informed consent. This research has also received approval from the Research Ethics Committee of the Faculty of Medicine, University of North Sumatra. Research Place at Mental Hospital Prof. Dr. M. Ildrem Medan, January - June 2019. Inclusion criteria: People with schizophrenia who meet the diagnosis criteria of PPDGJ-III., Male gender, Age between 25-40 years, Clinically stable phase and treatment for 6 months to with 2 years, duration of illness $\geq 5$ years, use of the antipsychotic Risperidone, moderate smoking, the latest education at least Junior High School or equivalent is willing to be a respondent. Exclusion criteria: history of depressive disorders, history of other medical disorders, and use of psychoactive substances and mental retardation.

\section{MEASURMENT}

\section{Positive and Negative Syndrome Scale (PANSS)}

The Positive and Negative Syndrome Scale (PANSS) is a medical scale used to measure the symptom severity of patients with schizophrenia. Of the 30 parameters assessed, seven were selected to form a positive scale (score range 7-49), seven negative scales (7-49), and the remaining 16 constitute a general psychopathological scale (16-112). Each was rated as $1=$ none, 2 $=$ minimal, $3=$ mild, $4=$ moderate, $5=$ moderate, $6=$ severe and 7 = very heavy. 30 items were organized as 7 items for positive symptoms (P1-P7), 7 items for negative symptoms (N1-N7), and 16 items for general psychopathology (G1-G16). Dominant negative symptoms were defined as: Baseline score $\geq 4$ on at least 3 , or $\geq 5$ on at least 2 items on the negative PANSS subscale. Nondominant negative symptoms were defined as a score $\leq 3$ on the PANSS negative subscale or a negative total score $\leq 21[5]$.

\section{Montreal Cognitive Assessment (MoCA)}

The Montreal Cognitive Assessment (MoCA) was developed in 2005 as a screening tool for detecting individuals with mild cognitive impairment. Montreal Cognitive Assessment (MoCA) was developed according to the target domain of impairment values most often found in mild cognitive impairment. MoCA-INA consists of domains: Visuospatial / executive (i), Visuospatial / executive (cube), Visuospatial / executive (clock), Naming, Memory, Attention, Repetition of sentences, Verbal fluency, Abstraction, Delayed memory (delayed recall), Orientation. Add one point for subjects with less than 12 years of formal education background. The maximum score generated is 30 , for a total score $>26$ is normal (no interference). MoCA has a sensitivity of $90 \%$ and a specificity of $87 \%$ for assessing cognitive function [6], [7].

\section{Personal and Social Performance Scale (PSP)}

To assess personal and social function in schizophrenic patients, the Personal and Social Performance Scale (PSP) was developed through focus groups and a reliability study by Morosini et al in 2000 in Rome, Italy. The focus groups identified 27 different areas of personal and social dysfunction, which were included in four domains: socially beneficial activities, personal and social relationships, self-care, destructive and aggressive behavior. The overall scoring of all scores ranged from 1 (maximal dysfunction) to 100 (maximum functioning), based on the scores obtained in each domain. A total score over 70 indicates a condition of functional remission, with a score associated with overall good functioning [8].

\section{STATISTIC ANALYSIS}

Data were analyzed using the SPSS tool to determine the comparison in demographic characteristics of the two sample groups using the Mann Withney $U$ analysis test (because the data were not normally distributed, previously data normality was carried out with log transformation), Chi Square test, and Fisher's test. Apart from comparing the two groups based on demographic characteristics, the results of this study were also analyzed based on differences in the total MoCA-INA score and PSP scores in the two groups. 


\section{RESULT}

Table 1. Demographic characteristics of schizophrenic male based on the negative symptom PANSS score

\begin{tabular}{|c|c|c|c|}
\hline Demographic characteristics & $\begin{array}{l}\text { Schizophrenic male } \\
\text { with Dominant Negative } \\
\text { Symptoms }(n=40)\end{array}$ & $\begin{array}{l}\text { Schizophrenic male with } \\
\text { Non-Dominant Negative } \\
\text { Symptoms } \\
(\mathbf{n = 4 0})\end{array}$ & $p$ \\
\hline $\begin{array}{l}\text { Age (Years) } \\
\text { Median } \\
\text { (minimum-maximum) }\end{array}$ & $\begin{array}{l}35,50 \\
(25,00-40,00)\end{array}$ & $\begin{array}{l}37,00 \\
(25,00-40,00)\end{array}$ & $0,358^{a}$ \\
\hline $\begin{array}{l}\text { Duration of Illness (Years) } \\
\text { Median } \\
\text { (minimum-maksimum) }\end{array}$ & $\begin{array}{l}6,50 \\
(5,00-10,00)\end{array}$ & $\begin{array}{l}7,00 \\
(5,00-10,00)\end{array}$ & $0,399^{\mathrm{a}}$ \\
\hline $\begin{array}{l}\text { Level of Education n }(\%) \\
\text { Junior high school } \\
\text { Senior high school, Bachelor }\end{array}$ & $\begin{array}{l}24(60,0 \%) \\
16(40,0 \%)\end{array}$ & $\begin{array}{l}23(57,5 \%) \\
17(42,5 \%)\end{array}$ & $1,000^{\mathrm{b}}$ \\
\hline $\begin{array}{l}\text { Marital Status n (\%) } \\
\text { Married } \\
\text { Unmarried }\end{array}$ & $\begin{array}{l}12(30,0 \%) \\
28(70,0 \%)\end{array}$ & $\begin{array}{l}16(40,0 \%) \\
24(60,0 \%)\end{array}$ & $0,428^{\mathrm{b}}$ \\
\hline $\begin{array}{l}\text { Employed status n (\%) } \\
\text { Employed } \\
\text { Unemployed }\end{array}$ & $\begin{array}{l}13(32,5 \%) \\
27(67,5 \%)\end{array}$ & $\begin{array}{l}16(40,0 \%) \\
24(60,0 \%)\end{array}$ & $0,642^{\mathrm{b}}$ \\
\hline $\begin{array}{l}\text { Smoking history n (\%) } \\
\text { No smoking } \\
\text { light smokers and moderate smokers }\end{array}$ & $\begin{array}{l}5(12,5 \%) \\
35(87,5 \%)\end{array}$ & $\begin{array}{l}2(5,0 \%) \\
38(95,0 \%)\end{array}$ & $0,432^{\mathrm{c}}$ \\
\hline PANSS score & $\begin{array}{l}60,00 \\
(57,00-66,0)\end{array}$ & $\begin{array}{l}47,00 \\
(40,00-54,00)\end{array}$ & $<0,001^{\mathrm{a}}$ \\
\hline CDSS score* & $\begin{array}{l}1,00 \\
(0,00-3,00)\end{array}$ & $\begin{array}{l}0,00 \\
(0,00-3,00)\end{array}$ & $0,018^{\mathrm{a}}$ \\
\hline
\end{tabular}

${ }^{\mathrm{a} M a n n-\text { Withney U Test }}$

${ }^{\mathrm{b}}$ Chi Square Test (Continuity Correction)

${ }^{\mathrm{c}}$ Fisher Test

*CDSS : Calgary Depression for Schizophrenia

Table 2. Comparison of the Montreal Cognitive Assessment Score Indonesian Version (MOCA INA) in Schizophrenic male with Dominant Negative Symptoms and Non-Dominant Negative Symptoms

$\begin{aligned} & \text { Comparison of the Montreal Cognitive } \\ & \text { Assessment Score Indonesian Version (MOCA }\end{aligned}$
INA)

*Mann-Withney U Test

There was no difference in the MoCA-INA score between schizophrenic male with dominant negative symptoms and non- dominant negative symptoms. The median MoCA-INA score for schizophrenic male with dominant negative symptoms is 20.00 
with the minimum total score is 16.00 and the maximum total score is 24.00. The median MoCA-INA score for schizophrenic male with non-dominant negative symptoms was 21.50 with a minimum total score of 16.00 and a maximum total score of 26.00 with $\mathrm{p}=0.114$.

\section{Table 3. Comparison of the Personal and Social Performance Scale (PSP) scores in Schizophrenic male with Dominant Negative Symptoms and Non-Dominant Negative Symptoms}

\begin{tabular}{llllll}
\hline $\begin{array}{l}\text { Comparison of the Personal and Social } \\
\text { Performance Scale (PSP) scores }\end{array}$ & $\begin{array}{l}\text { Median } \\
\text { (minimum-maximum) }\end{array}$ & $\boldsymbol{p}$ \\
\hline $\begin{array}{l}\text { Schizophrenic male with Dominant Negative } \\
\text { Symptoms }\end{array}$ & & & $\begin{array}{l}55,00 \\
(45,00-70,00)\end{array}$ & 0,174 \\
\end{tabular}

Schizophrenic male with Non-Dominant Negative $\quad 40 \quad 56.50$ Symptoms

*Mann-Withney U Test.

$(45,00-71,00)$

There was no difference in the PSP score between schizophrenic male with dominant negative symptoms and nondominant negative symptoms. The median PSP score for schizophrenic male with dominant negative symptoms is 55.00 with the minimum total score is 70.00 and the maximum total score is 45.00 . The median MoCA-INA score for schizophrenic male with non-dominant negative symptoms was 56.50 with a minimum total score of 71.00 and a maximum total score of 45.00 with $\mathrm{p}=0.174$.

\section{DISCUSSION}

In this present study, we found that there was no difference in the MoCA-INA and PSP score score between schizophrenic male with dominant negative symptoms and non-dominant negative symptoms.

A study conducted by Han and colleagues in 2012 in China, from a study they conducted on 122 male schizophrenic groups, the age of the sample taken was 25-70 years with a mean age of 51.6 years. The results showed that the cognitive variables assessed by RBANS were associated with negative symptom scores or total PANSS in the male schizophrenic group with a $p$ value $<0.01$. The cognitive variables that experienced a decline in scores in Han et al's study were immediate memory with a mean of $59.9 \pm 18.1$, delayed memory with a mean of $66.6 \pm 20.3$ and a total RBANS score with a mean of $68.6 \pm 16.0$. Low education, severe negative symptoms, old age, smoking, length of illness, and male gender are associated with cognitive function in schizophrenia [9].

A study conducted by Savilla and colleagues in 2008 in Australia, from the study they conducted in the schizophrenia group aged 21-55 years, it was found that poor cognitive function was associated with the severity / increase of negative symptoms with a $\mathrm{p}$ value $<0.05$. Cognitive variables measured by BACS in the sample group that experienced a decrease in score were verbal memory with a mean of $30.96 \pm 11.37$, working memory with a mean of $17.19 \pm 5.55$, motor function with a mean of $58.18 \pm$ 17.67. , attention and speed of information processing with a mean of $40.25 \pm 13.40$, verbal fluency with a mean of $42.25 \pm 14.39$, executive function with a mean of $14.11 \pm 4.30$. Worse cognitive function was found to be moderate and significant associated with more severe negative symptoms of schizophrenia. Schizophrenia is associated with multifaceted cognitive deficits, most prominently in the areas of attention, memory and executive function and social cognition. Schizophrenia has a devastating effect on nearly every aspect of a person's life and is associated with significant social, psychological and occupational dysfunction [10].

One of the factors that cause cognitive dysfunction is age. The older the age, the more impaired cognitive function. In our study, there was no difference in MoCA-INA scores in the two sample groups, possibly because the age of the study sample was included in the young age group so that cognitive function in the two groups was not significantly different. From a study conducted by Fucetola and colleagues in 2000 in Boston on 3 groups of schizophrenia based on age, namely: the young age group with a mean age of $30.0 \pm 3.6$, the middle age group with a mean age of $41.1 \pm 4.2$, and the old age group with a mean age of $58.3 \pm 5.6$. From the results of their study, it was found that cognitive function in people with schizophrenia decreased in all age groups but a very clear decline was in the middle age group and the old age group. Where the difference in cognitive function between the young age group and the old age group with a value of $p=0.001$. The difference in cognitive function between the middle age group and the old age group with a value of $p=0.037$ [11].

Bagney and colleagues in 2015 in Spain, from the results of their study, found no relationship between negative symptom PANSS scores with cognitive domains and MCCB composite scores with $\mathrm{p}=0.289$. According to Bagney, this is due to overlapping definitions of the construction of negative PANSS factors and the selection of assessment instruments used in a study. To assess the severity of symptoms, Bagney and colleagues used the PANSS five factor consensus model instrument from the National Institute of Mental Health (NIMH) and to assess cognitive function the assessment instrument used was the MCCB. The similarity found in the study conducted by Bagney and colleagues is that their study is a study with a cross sectional approach, stable phase (no hospitalization, no change in treatment and no change from psychopathology for at least 6 months) [12]. 
Strassing and colleagues in 2014 in the United States, in this study to assess functional outcomes using the Specific Levels of Functioning (SLOF) instrument which is divided into 3 variables, namely: daily activity function variables, vocational variables and interpersonal variables. From the study they conducted, it was found that the study results for the variable daily activity function were not different between the schizophrenia group with negative symptoms with moderate severity (score $\geq 4$ ) and the schizophrenia group with negative symptoms with mild severity (score $\leq 3$ ) with $p=0$. 06. In the vocational function variable, there was also no difference between the group of schizophrenia patients with negative symptoms with moderate severity and the schizophrenia group with negative symptoms with mild severity with $\mathrm{p}$ value $=0.32$. However, in the interpersonal function variable, there was a difference between the schizophrenia group of negative symptoms with moderate severity and the schizophrenia group with negative symptoms with mild severity with a $\mathrm{p}$ value $<0.001$. This may be because they used 2 model factors from the negative symptom model, namely: PANSS Reduced Expression and PANSS. Reduce Emotional Experience and the difference in measurement tools used in this study where in this study the functional outcome uses the SLOF measurement tool where the SLOF assessment is divided into 3 separate variables, namely daily activity function variables, vocational variables and interpersonal variables so that it will be seen which variables are functional. The ODS outcome was different in the two sample groups [13].

The strength of this study is that it managed to control all confounding factors such as age, length of illness, education level, employment status, marital status, daily cigarette use and CDSS score. As far as the literature searches so far, this study is the first study to see differences in Moca-INA scores and PSP scores in schizophrenic male with dominant negative symptoms and nondominant negative symptoms in Indonesia. The limitation of this study is, this study was only conducted at one study site and was not a multi-center study.

\section{ACKNOWLEDGEMENT}

The authors thanked participants who volunteered for this study and people who participated in the data collection. The authors declare no potential conflict of interest in writing this original article.

\section{REFERENCES}

[1] Tsapakis, E.M, Dimopoulou T, Tarazi FI. Clinical management of nrgative symptoms of schizophrenia: An update, Pharmachology \& Therapeutics. 2015; p.1-13

[2] Nasrallah H, Morosini PL, Gagnon DD. Reliability, validity and ability to detect change of the Personal and Social Performance scale in patients with stable schizophrenia. Psychiatry Research. 2008; 161: p. 213-24.
[3] Barabassy A, Szatmári B, Laszlovszky I, Németh G. Negative Symptoms of Schizophrenia: Constructs, Burden, and Management. Intech Open. 2018; p:43-62.

[4] Kaneko K. Negative Symptoms and Cognitive Impairments in Schizophrenia: Two Key Symptoms Negatively Influencing Social Functioning. Yanago Acta Medica. 2018; 61:091-102

[5] Opler LA, Opler MG, Malaspina D. Reducing guesswork in schizophrenia treatment. PANSS can target and gauge therapy, predict outcomes. Current psychiatry Vol.5, No.9. 2006.

[6] Maust D, Cristancho M, Gray L, Rushing S, Tjoa C, Thase M. Psychiatric rating scales. Handbook of Clinical Neurology, Vol. 106 (3rd series). Neurobiology of Psychiatric Disorders. T.E Schlaepfer and C.B. Nemeroff, Editors. Elsevier B.V. 2012.

[7] Nasreddine ZS, Phillips NA, Be'dirian V, Charbonneau S, Whitehead V, Collin I, Cummings J, Chertkow H. The Montreal Cognitive Assessment, MoCA: A Brief ScreeningTool For Mild Cognitive Impairment. Brief methodological reports. American Geriatrics Society. 2005; 53:695-99

[8] Morisini P-L, Magliano L, Brambilla L, Ugolini S, Pioli R. Development, Reliability and Acceptability Of A New Version Of The DSM-IV Social and Occupational Functioning Assessmen Scale (SOFAS) To assess Routine Social Functioning. Acta Psychiatry. Scand.2000;101:p.323-9.

[9] Han M, Huang XF, Chen DC, Xiu MH, Hui L, Liu Het al. Gender differences in cognitive function of patients with chronic schizophrenia. Progress in Neuro-Psychopharmacology \& Biological Psychiatry. 2012; 39: 358-63.

[10] Savilla K, Kettler L, Galletly C. Relationships between cognitive deficits, symptoms and quality of life in schizophrenia.The Royal Australian and New Zealand College of Psychiatrists. 2008; p:496-504.

[11] Fucetola R, Seidman LJ, Kremen WS, farone SV, Goldstein JM, Tsuang MT Age and neuropsychologic function in schizophrenia: A decline in executive abilities beyond that observed in healthy volunteers. Society of Biological Psychiatry.2000.

[12] Bagney A, Dompablo M, Santabarbara J, Ortega MM, Lobo A, Ariero MAJ, Palomo T, Jimenez RR. Are negative symptoms really related to cognition in schizophrenia?. Psychiatry Reseach. 2015.

[13] Strassnig M, Bowie C, Pinkham AE, Penn D, Twamley EW, Patterson TL, Harvey PD. Which level of cognitive impairments and negative symptoms are related to fungtional deficits in schizophrenia?.Journal of Psychiatric Research. 2018.

\section{AUTHORS}

First Author - Huzaipah, Department of Psychiatry, Faculty of Medicine, Universitas Sumatera Utara, Medan, Indonesia

Second Author - Bahagia Loebis, Department of Psychiatry, Faculty of Medicine, Universitas Sumatera Utara, Medan, Indonesia

Third Author - Vita Camellia, Department of Psychiatry, Faculty of Medicine, Universitas Sumatera Utara, Medan, Indonesia

Correspondence: Huzaipah. Department of Psychiatry, Faculty of Medicine, Universitas Sumatera Utara, Medan, Indonesia. E-mail: huzaipahdr@gmail.com

Orchid ID: https://orcid.org/0000-0002-2390-5465 